chemotherapy, or failed diagnosis from less-invasive modalities. However, even if this is the case, the principal findings of the study are important: Surgical management of primary cardiac lymphoma was not associated improved survival, whereas chemotherapy was associated with improved survival. ${ }^{1}$

Other studies evaluating this rare disease are limited by heterogenous patient populations, small institutional series, or case reports. Perhaps the most robust data can be found in a meta-analysis from Petrich and colleagues ${ }^{2}$ in the medical oncology literature. The authors compiled 197 cases of primary cardiac lymphoma from 166 separate articles and found that $72 \%$ of patients underwent chemotherapy, $28 \%$ underwent surgical debulking or resection, and $20 \%$ underwent radiation. Similar to the current study, the authors found a significant survival benefit in those who underwent chemotherapy (median overall survival for those who received chemotherapy of 30 months $[\mathrm{n}=105]$ vs 0.3 months in those who did not $[\mathrm{n}=23] ; P<.0001){ }^{2}$ Further, they found no survival benefit to those who underwent surgery compared with those who did not undergo surgery (median survival, 22 months vs 10 months; $P=.18$ ). The second largest series identified 94 patients with cardiac lymphoma, 51 of whom had primary cardiac lymphoma. Those who underwent chemotherapy had a median survival of 18 months versus 1 month for those who did $\operatorname{not}(P=.0003)$, whereas only 4 patients underwent surgery and their outcomes were not reported.

Although these studies are limited by inconsistent inclusion and exclusion criteria, incomplete data, and selection and publication bias, the rarity of the disease makes large, randomized data impossible. Nonetheless, the current study supports the limited data in the literature that suggest surgery for primary cardiac lymphoma should be reserved for special circumstances and is unlikely to have an influence on survival.

\section{References}

1. Yin K, Brydges H, Lawrence KW, Wei Y, Karlson KJ, McAneny DB, et al. Primary cardiac lymphoma. J Thorac Cardiovasc Surg. 2022;164:573-80.e1.

2. Petrich A, Cho SI, Billett H. Primary cardiac lymphoma: an analysis of presentation, treatment, and outcome patterns. Cancer. 2011;117:581-9.

3. Gordon MJ, Danilova O, Spurgeon S, Danilov AV. Cardiac non-Hodgkin's lym phoma: clinical characteristics and trends in survival. Eur J Haematol. 2016;97: 445-52.

\title{
Commentary: Primary cardiac lymphoma: Chasing rarity
}

\author{
Edgar Aranda-Michel, BS, ${ }^{\mathrm{a}}$ and \\ Ibrahim Sultan, MD ${ }^{\mathrm{a}, \mathrm{b}}$
}

Primary cardiac lymphoma is an exceedingly rare cancer, accounting for only $1 \%$ to $2 \%$ of all primary cardiac tumors. ${ }^{1}$ Owing to its rarity, no consensus on management

\footnotetext{
From the a Division of Cardiac Surgery, Department of Cardiothoracic Surgery, University of Pittsburgh and ${ }^{\mathrm{b}}$ Heart and Vascular Institute, University of Pittsburgh Medical Center, Pittsburgh, $\mathrm{Pa}$.

Disclosures: Dr Sultan receives institutional research support from AtriCure and Medtronic unrelated to this work. Mr Aranda-Michel has reported no conflicts of interest.

The Journal policy requires editors and reviewers to disclose conflicts of interest and to decline handling or reviewing manuscripts for which they may have a conflict of interest. The editors and reviewers of this article have no conflicts of interest.

Received for publication Sept 26, 2020; revisions received Sept 26, 2020; accepted for publication Sept 28, 2020; available ahead of print Sept 12, 2020.

Address for reprints: Ibrahim Sultan, MD, Division of Cardiac Surgery, Department of Cardiothoracic Surgery, University of Pittsburgh, Center for Thoracic Aortic Disease, Heart and Vascular Institute, University of Pittsburgh Medical Center, 5200 Centre Ave, Suite 715, Pittsburgh, PA 15232 (E-mail: sultani@upmc.edu). J Thorac Cardiovasc Surg 2022;164:583-4 $0022-5223 / \$ 36.00$

Copyright (c) 2020 by The American Association for Thoracic Surgery http://dx.doi.org/10.1016/j.jtcvs.2020.09.116
}

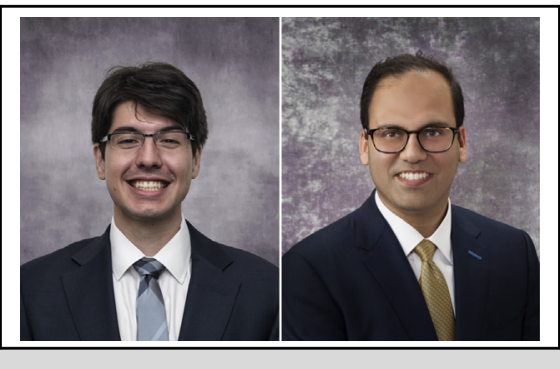

Edgar Aranda-Michel, BS, and Ibrahim Sultan, MD

CENTRAL MESSAGE

Although primary cardiac lymphoma continues to have dismal outcomes, chemotherapy is the sole treatment with a survival benefit.

exists. In their article in this issue of the Journal, Yi and colleagues ${ }^{2}$ have attempted to further elucidate this disease by leveraging a large national cancer database. Their primary 
findings are the dismal outcomes in this patient population, with chemotherapy the sole modality that improves outcomes, and a lack of improvement in outcomes based on the year of diagnosis. With rare diseases, larger studies have a greater potential for increased confounding in the analysis due to heterogeneity in treatments as well as large time spans of the cohorts. Results from these types of analysis should be considered in this overall context. Despite this, the authors should be commended on a wellexecuted study that contributes much-needed data to the field of primary cardiac lymphoma.

The authors identified chemotherapy as the sole treatment modality that conferred a survival benefit. This can be attributed to the fact that most chemotherapy cases occurred in the contemporary setting, with a substantial proportion of patients receiving chemotherapy after 2010. Rituximab was added to the CHOP regimen for non-Hodgkin's lymphoma in 2010 and has shown improved progression-free survival in B cell lymphoma, which represents the majority of subtypes in this patient cohort. ${ }^{3}$ In contrast, surgery was shown to provide no survival benefit. This finding is characteristic of primary cardiac lymphoma, as we demonstrated in a recent large study of primary cardiac tumors showing improved survival with completeness of resection. ${ }^{4}$ A possible explanation for this finding is that the surgical management was reserved for patients requiring palliative procedures. More than one-quarter of this cohort was in stage IV, and although not examined in this study, it is possible many of these surgeries were done in this subset of patients. Moreover, only local or partial resection was performed, suggesting more of a palliative approach than a curative approach. Taken together, these factors imply that surgery in this population is not without its uses and its lack of survival benefit is more reflective of the patient prognosis than the surgery itself, because it is reserved for certain circumstances.

Undoubtably there is much room for improvement. With the standard chemotherapeutic regimen being relatively unchanged from 2010 and surgical intervention done sparingly, it is unsurprising that outcomes remain dismal and relatively unchanged, despite the improvements in imaging technology. However, a clear trend of the benefit of chemotherapy in this cohort cannot be overstated. ${ }^{6}$ As such, early diagnosis of the mass is imperative to determine the cell type and choose the appropriate treatment. Unfortunately, determining the appropriate treatment in this cohort is challenging. While strong evidence exists for the efficacy of chemotherapy, the roles of surgery and radiation are much less well understood owing the heterogenous treatments in the literature. Further large studies are needed to elucidate these critical questions, an endeavor well addressed by these authors.

\section{References}

1. Chen CF, Hsieh PP, Lin SJ. Primary cardiac lymphoma with unusual presentation: a report of two cases. Mol Clin Oncol. 2017;6:311-4.

2. Yin K, Brydges H, Lawrence KW, Wei Y, Karlson KJ, McAneny DB, et al. Primary cardiac lymphoma. J Thorac Cardiovasc Surg. 2022;164:573-80.e1.

3. Coiffier B, Thieblemont C, Van Den Neste E, Lepeu G, Plantier I, Castaigne S, et al. Long-term outcome of patients in the LNH-98.5 trial, the first randomized study comparing rituximab-CHOP to standard CHOP chemotherapy in DLBCL patients: a study by the Groupe d'Etudes des Lymphomes de l'Adulte. Blood. 2010;116:2040-5.

4. Sultan I, Bianco V, Habertheuer A, Kilic A, Gleason TG, Aranda-Michel E, et al. Long-term outcomes of primary cardiac malignancies: multiinstitutional results from the National Cancer Database. J Am Coll Cardiol. 2020;75:2338-47.

5. Jonavicius K, Salcius K, Meskauskas R, Valeviciene N, Tarutis V, Sirvydis V. Primary cardiac lymphoma: two cases and a review of literature. J Cardiothorac Surg. 2015; 10:138

6. Shin DY, Lee YG, Lee HJ, Choi S, Park JJ, Kim DW. Long-term disease-free survival of patients with primary cardiac lymphoma treated with systemic chemotherapy and radiotherapy. Korean J Hematol. 2010; $45: 282-5$. 